\title{
Advance directives and suicide attempts - ethical considerations in light of Carter v. Canada, SCC 5
}

\author{
Merril Pauls, MD, MHSc*; Gregory Luke Larkin, $\mathrm{MD}^{*} \mathrm{MSPh}^{\dagger}$; Raquel M. Schears, MD, $\mathrm{MPh}^{\ddagger}$
}

A 56-year-old female presents to the emergency department after an intentional overdose of a large number of long-acting verapamil tablets. She says she wants to die and has come to the emergency department because she doesn't want to die alone. She is bradycardic at $40 \mathrm{BPM}$, hypotensive at $100 / 60 \mathrm{~mm} \mathrm{Hg}$, and has a first-degree atrioventricular block on her electrocardiogram; findings are consistent with her stated ingestion. She says she does not want treatment for her ingestion. She presents an advance directive (AD) stating that she has chronic pain secondary to multiple endocrine tumors, and that she does not want life-sustaining treatments (such as intubation, ventilation, or cardiopulmonary resuscitation) under any circumstances. The document is signed, dated within the last 4 weeks, and notarized. Her level of consciousness decreases, and the treating team is unsure of their ethical and legal responsibilities in the face of her stated wishes and her $\mathrm{AD}$.

ADs are an important way patients tell us what they want when they can't speak for themselves. A person should have decision-making capacity when completing an $\mathrm{AD}$, and they only come into force when the person is incapable. ${ }^{1,2} \mathrm{An} \mathrm{AD}$ can identify whom the patient wants to speak for them, or can provide instructions regarding medical interventions that they do or do not want. The law says that a patient's advance authorization (or refusal) of even life-saving medical interventions should be treated the same as those of a capable patient. ${ }^{3}$ In turn, if a physician treats an incapable patient in a manner that is inconsistent or contrary to his or her $\mathrm{AD}$, that physician may be liable for assault and/or battery. ${ }^{4}$ Yet there are exceptional circumstances where we should question the validity of an $\mathrm{AD}$ and should not follow the wishes expressed. One of these is in the context of an apparent suicide attempt.

Suicide-related emergency department visits have become increasingly common over the past 20 years, ${ }^{5}$ and more Canadians die annually from suicide than from transport accidents and assaults combined. ${ }^{6}$ Numerous cases have been reported of patients who have attempted suicide and arrive in the emergency department with an $\mathrm{AD}$ stating that they do not want resuscitative interventions. ${ }^{7,8}$ Physicians may feel conflicted in these situations, trying to reconcile their initial instinct to resuscitate, and their professional responsibility to intervene with a suicidal patient, with the legal mandate to respect a patient's expressed wishes. Further complicating these situations is the professional debate ongoing in Canada as to the acceptability of physicianassisted suicide ${ }^{9,10}$ and the recent decision by the Supreme Court that declared the criminal prohibition against physician-assisted dying unconstitutional. ${ }^{11}$ Currently, four U.S. states allow physician-assisted suicide: Oregon, Washington, Vermont, and Montana.

Most emergency physicians have a natural inclination to resuscitate first and ask questions later. The emergency exception to informed consent is generally cited as the basis for this approach. If a patient is not capable, has a life- or limb-threatening condition, and a substitute decision-maker is not available, then we can (and should) proceed with treatment for emergent conditions. ${ }^{12}$ Yet there are circumstances where the

From the *Department of Emergency Medicine, College of Medicine, University of Manitoba, Winnipeg, MB; tDivision of Emergency Medicine, School of Medicine, University of Auckland, NZ; and $\neq$ Division of Emergency Medicine, College of Medicine, Mayo Clinic, Rochester, MN.

Correspondence to: Dr. Merril Pauls, Department of Emergency Medicine, College of Medicine, University of Manitoba, T258-770 Bannatyne Ave., Winnipeg, MB R3E 0W3; Email: pauls@cc.umanitoba.ca 
exemption thresholds for an emergency are crossed, but a patient has left clear directions that they would not want treatment. Some examples would be the patient with a known abdominal aortic aneurysm (AAA) who has declined surgery, or a Jehovah's Witness who does not want a blood transfusion under any circumstances. Even if these patients present with a life-threatening emergency (a ruptured AAA, or a life-threatening hemorrhage), they have expressed enduring wishes that they want followed in these very circumstances, and so these should generally be respected. ${ }^{13} \mathrm{~A}$ decision to proceed with resuscitation should not be based solely on the urgency of the medical condition; it must also consider whether an $\mathrm{AD}$ is present, and, if so, is it a valid $\mathrm{AD}$ that represents an enduring wish?

A second consideration is the context of the presentation. Does the fact that a patient has attempted suicide alter our legal and professional responsibilities regarding ADs? Every jurisdiction in North America has legislation that allows emergency physicians to hold a suicidal patient until they can be further assessed by a psychiatrist. ${ }^{14}$ An acutely suicidal patient generally has a mental health condition that impairs their capacity and their ability to make treatment decisions. Suicidal ideation is typically transient, and many of the underlying conditions that contribute to its development are treatable. ADs are intended to convey enduring wishes that represent the patient's core values. It is the very rare circumstance where a suicide attempt would meet these criteria, and it would be extremely difficult to verify this in the emergency department context, and so emergency physicians should generally treat suicidal patients despite an $\mathrm{AD}$ to the contrary. ${ }^{15,16}$

ADs have significant limitations. Clinicians assume a patient was capable when completing it but can rarely verify this. A patient's wishes may have changed from the time that he or she wrote it, and the patient may not have anticipated his or her current clinical situation, or current state of mind when completing it. However, in most situations, an $\mathrm{AD}$ matches what our clinical judgment would support (i.e., the terminally ill patients who do not want life-sustaining treatments) or we are able to verify the wishes with a substitute decisionmaker. When a vulnerable patient who has attempted suicide presents with an $\mathrm{AD}$, there are many reasons to question the validity of these documents, and few reasons to honor them in this setting.

The recent Supreme Court decision raises the possibility that Canadian emergency physicians may encounter patients who have attempted suicide as part of a legal and professionally sanctioned process. Although most patients who proceed with physician-assisted suicide would be expected to die outside of the hospital, it is possible that some may not die after taking their medication, or may develop distressing symptoms while dying. Family or friends may call an ambulance or transfer them to the ED. It would be crucial that the patient has clear and accessible documentation establishing that they met predetermined criteria for medical assistance in dying. The emergency physician must be able to quickly and unambiguously establish that this was a legal act that occurred only after appropriate assessment of the patient, both to ensure that vulnerable patients are not denied appropriate care, and to provide protection for emergency physicians against a legal action or professional complaint. It is also very important for physicians to understand that the Supreme Court suspended its decision for 12 months in order to give Parliament and provincial legislatures time to enact legislation. Regulatory authorities and medical associations also need to develop policies and guidelines. This means that, at the current time, in Canada, it remains illegal for a physician to counsel, aid, or abet a person to commit suicide. ${ }^{17}$

\section{SUMMARY}

1. ADs are an important way that our patients tell us what they want when they cannot speak for themselves.

2. Emergency physicians are generally expected to follow the instructions in an $\mathrm{AD}$, as this shows respect for patient autonomy and is consistent with the law.

3. There will be rare cases in which a patient's AD instructs the physician to withhold treatment that the physician feels may be helpful or beneficial.

4. Patients with decisional capacity have the right to refuse even life-saving treatments if this refusal represents an informed and enduring wish. An urgent need for treatment does not provide justification to override valid refusals or deny requests from patients with ADs.

5. Suicidal ideation is generally transient and often associated with a treatable mental illness. An $\mathrm{AD}$ requesting treatment be withheld in the context of a suicide attempt should generally not be considered an informed or enduring wish, and life-sustaining treatment should be initiated. 
6. Current professional and legal standards when faced with a patient who has attempted suicide are to 1) initiate indicated treatments and 2) hold the patient for psychiatric assessment, even if he or she has a valid $\mathrm{AD}$ that asks that treatment be withheld.

7. In the near future, patients may be brought to the ED who have attempted physician-assisted suicide. In these very rare cases, the emergency physician must ensure that the patient met predetermined eligibility criteria and that it has been clearly documented prior to withholding resuscitative interventions.

Keywords: suicide, advance directive, emergency department

Competing interests: None declared.

\section{REFERENCES}

1. Marco CA, Schears RM. Death, dying, and last wishes. Emerg Med Clin North Am 2006;24(4):969-87.

2. Olick RS. Defining features of advance directives in law and clinical practice. Chest 2012;141(1):232-8.

3. Peppin P. Informed consent. In Downie J, Caulfield T, Flood CM (eds.) Canadian bealth law and policy. 4th ed. Ontario: LexisNexis; 2011: 159-62.

4. Malette v. Shulman (Ont. C.A.), 1990 CanLII 6868 (ON CA) (accessed 16 June 2015).

5. Larkin GL, Smith RP, Beautrias AL. Trends in suiciderelated visits to emergency departments. Crisis 2008; 29(2):73-80.

6. Bethell J, Rhodes AE. Identifying deliberate self-harm in emergency department data. Health Reports 2009;20(2): $35-42$.
7. David AS, Hotopf M, Moran P, et al. Mentally disordered or lacking capacity? Lessons for managing serious deliberate self harm. BM7 2010;341(7773):587-9.

8. Dresser R. Suicide attempts and treatment refusals. Hastings Center Report 2010;40(3):10-11.

9. Bill No. 52- An Act respecting end-of-life care. Passed by the Quebec National Assembly on June 5th, 2014; 2014. Available at: http://www.assnat.qc.ca/en/travauxparlementaires/projets-loi/projet-loi-52-40-1.html (accessed 17 March 2015).

10. Doctor-assisted suicide a therapeutic service, says Canadian Medical Association. CBC News Online; 2015. Available at: http://www.cbc.ca/news/health/doctor-assisted-suicidea-therapeutic-service-says-canadian-medical-association1.2947779 (accessed 17 March 2015).

11. Carter v. Canada (Attorney General), 2015 SCC 5 (CanLII) (accessed 16 June 2015).

12. Palmer RB, Iserson KV. The critical patient who refuses treatment: an ethical dilemma. 7 Emerg Med 1997;15(5): 729-33.

13. Woolley SJ. Jehovah's Witnesses in the emergency department: what are their rights? 7 Emerg Med 2005;22 (12):869-71.

14. Carver P. Law and mental illness in Canada. In Irvine JC, Osborne PH, Shariff MJ (eds.) Canadian medical law - an introduction for physicians, nurses, and other bealth care professionals. 4th ed. Toronto (ON): Carswell; 2013: 297-305.

15. George F, Blackall A, Rebecca L, et al. After the suicide attempt: offering patients another chance. Am 7 Bioeth 2013;13(3):14-6.

16. Muzaffar S. To treat or not to treat. Kerrie Wooltorton, lessons to learn. $\mathcal{F}$ Emerg Med 2011;28(9):741-4.

17. The Canadian Medical Protective Association. What the Supreme Court of Canada decision on physician-assisted dying means for physicians; 2015. Available at: https://www. cmpa-acpm.ca/en/highlights/-/asset_publisher/ayugnUV1e $\mathrm{cYX} /$ content/what-the-supreme-court-of-canada-decision-onphysician-assisted-dying-means-for-physicians (accessed 17 March 2015). 